\title{
Characteristic Variations of VLF/LF Signals during a High Seismic Activity in Japan in November 2016
}

\author{
Tomokazu Asano1, Alexander Rozhnoi², Maria Solovieva², Masashi Hayakawa1,3 \\ ${ }^{1}$ Hayakawa Institute of Seismo Electromagnetics Co. Ltd. (Hi-SEM), UEC (University of Electro-Communications) \\ Alliance Center \#521, Tokyo, Japan \\ ${ }^{2}$ Institute of Physics of the Earth, Russian Academy of Sciences, Moscow, Russia \\ ${ }^{3}$ UEC Advanced Wireless \& Communications Research Center, Tokyo, Japan \\ Email: hayakawa@hi-seismo-em.jp
}

How to cite this paper: Asano, T., Rozhnoi, A., Solovieva, M. and Hayakawa, M. (2017) Characteristic Variations of VLF/LF Signals during a High Seismic Activity in Japan in November 2016. Open Journal of Earthquake Research, 6, 204-215. https://doi.org/10.4236/ojer.2017.64013

Received: September 21, 2017 Accepted: October 31, 2017

Published: November 3, 2017

Copyright (c) 2017 by authors and Scientific Research Publishing Inc. This work is licensed under the Creative Commons Attribution International License (CC BY 4.0)

http://creativecommons.org/licenses/by/4.0/

\begin{abstract}
The measurements of very low frequency/low frequency (VLF/LF) signals at the Petropavlovsk-Kamchatsky (PTK) and Yuzhno-Sakhalinsk (YSH) stations in Russia and several observing stations in Japan were used for the analysis of lower ionospheric perturbations in possible association with two earthquakes (EQs) which occurred offshore the Pacific Ocean of Japan in November 2016. The first EQ with $\mathrm{M}$ (magnitude) $=6.1$ (depth $42 \mathrm{~km}$ ) happened close to the coast line on 11 November (UT). The second EQ was recorded in the sea on 21 November (UT) with $\mathrm{M}=6.9$ (depth $11 \mathrm{~km}$ ) and they had a series of aftershocks with $\mathrm{M}$ up to 5.6. As for the long-range monitoring, the significant negative nighttime amplitude decreases as propagation anomalies were found for two subionospheric paths: NWC (Australia)-PTK and JJY (Fukushima, Japan)-YSH during about a week, mainly before the first EQ. The anomalies of signal in the path JJY-PTK were observed $4-5$ days before the second EQ and 3 days after it. Extensive analyses have been performed as well for these two EQs by using the short-range monitoring of VLF data observed at all of the seven VLF/LF stations in Japan in relation to the JJY signal. As related with the 1st EQ, there were observed anomalies on the two paths of JJY-STU (Suttsu) and JJY-NSB (Nakashibetsu) (both stations in Hokkaido) on 2 and 3 November. While, for the 2nd EQ clear anomalies have been observed on 14 and 15, and on 21 November at Ito station in Izu peninsula, Kamakura, Togane and Katsuura in Chiba. Taking into account the possible influence of other factors which can produce perturbations in VLF/LF signals and also using control paths, we may conclude that observed anomalies were very likely to be signatures of lower ionospheric perturbations caused by impending EQs. Finally, we try to estimate the possible perturbation scale for both EQs.
\end{abstract}




\section{Keywords}

VLF/LF Propagation Anomalies, İonospheric Perturbations, Earthquake Precursor, Short- and Long-Range Monitoring

\section{Introduction}

There has been an enormous progress in the field of seismo-electromagnetics (e.g., [1] [2]), and it is a general consensus that electromagnetic effects not only in the lithosphere, but also in the atmosphere and ionosphere do appear prior to an EQ. Especially, the ionospheric perturbations in the lower ionosphere [3] as well as in the upper F region (e.g., [4]) are found to be statistically correlated with earthquakes (EQs) with larger magnitude (M) and shallower depth. A few hypotheses have been proposed so far on the mechanism of lithosphere-atmosphereionosphere (LAI) coupling [1] [5] [6], but which mechanism is more plausible, is still poorly understood because it would be difficult to give observational evidence to any hypothesis because of the limited amount of observations and extensive further works are highly required for each hypothesis. Also, there have been some attempts to infer what is happening in the lithosphere prior to an EQ as the primary agent of LAI coupling. In addition to the conventional seismological model [1], Eftaxias et al. (2017) [7] have proposed a four-stage model of EQ generation in terms of fracture-induced electromagnetic emissions with paying attention to criticality.

The use of subionospheric VLF/LF signals enables us to study extensively the lower ionospheric perturbations, which is found to be very sensitive to the pre-EQ effects. Hayakawa et al. (1996) [8] found the convincing evidence of ionospheric perturbation for the 1995 Kobe EQ. Since then, there have been published a huge amount of papers on the VLF use for the study of ionospheric perturbations [9]-[17].

There are two ways of research direction for any of seismo-electromagnetic phenomena: Case and statistical study. Statistical studies on VLF propagation anomalies have been done [3] [9] [10] [18] [19] [20], which have indicated a close correlation between VLF propagation anomalies and EQs.

Though recognizing the importance of statistical studies, case studies still remain valuable, because we can obtain the detailed information on the ionospheric perturbation and its association with other phenomena for different EQs. Huge EQ events have been treated, including the 1995 Kobe EQ [8], the 2007 Niigata-chuetsu EQ [21] [22], the 2014 Sumatra EQ [23] [24], the 2011 Tohoku EQ [25] [26].

The present paper will present VLF/LF results for the high seismic activity in the Pacific Ocean side of Japan (presumably aftershocks of the 2011 Tohoku EQ) in November of 2016, because an EQ with M 6 and a relatively large EQ with M of 6.9 happened in the sea. Two EQs in November, 2016 have been treated in 
order to find out some precursory behavior in VLF data observed not only in Russia, but also in Japan. A combination of those data seen from far away from Russia (long-range monitoring) and observed at several stations in Japan (shortrange monitoring) must be of great importance in finding the structure of the ionospheric perturbation.

\section{EQs Treated in This Paper}

The seismic activity in the Pacific Ocean side of Japan is decreasing as a general tendency after the 2011 Tohoku EQ, but sometimes we have rather strong EQs, which are probably presumed to be aftershocks of the 2011 Tohoku EQ. Figure 1 illustrates the positions of two EQs in November, 2016; One EQ happened off-shore of Miyagi prefecture, but close to the sea coast (geographic coordinates: $38^{\circ} 27.8^{\prime} \mathrm{N}, 141^{\circ} 36.4^{\prime} \mathrm{E}$ ) at 22:43:00.7 on 11 November (UT) (06:43:00.7 on 12 November (JST)), and was not so huge because its M was 6.1 (depth $10 \mathrm{~km}$ ). And the next large EQ took place well in the sea at the geographic location $\left(37.392^{\circ} \mathrm{N}, 141.403^{\circ} \mathrm{E}\right)$ at $20: 59: 49 \mathrm{UT}$ on 21 November (05:59:49 JST on $22 \mathrm{No}-$ vember), which was rather strong enough to have an $M$ of 6.9 and depth of 11 $\mathrm{km}$. The EQ epicenter is close to the Japanese VLF transmitter, JJY (geographic coordinates: $\left.37.22^{\circ} \mathrm{N}, 140.51^{\circ} \mathrm{E}\right)$ in Fukushima $(\mathrm{f}=40 \mathrm{kHz})$.

\section{VLF/LF Equipment}

The data from two Russian VLF/LF stations are treated in this paper: One is Petropavlovsk-Kamchatsky (abbreviated as PTK, $53.09^{\circ} \mathrm{N}, 158.55^{\circ} \mathrm{E}$ ) and another

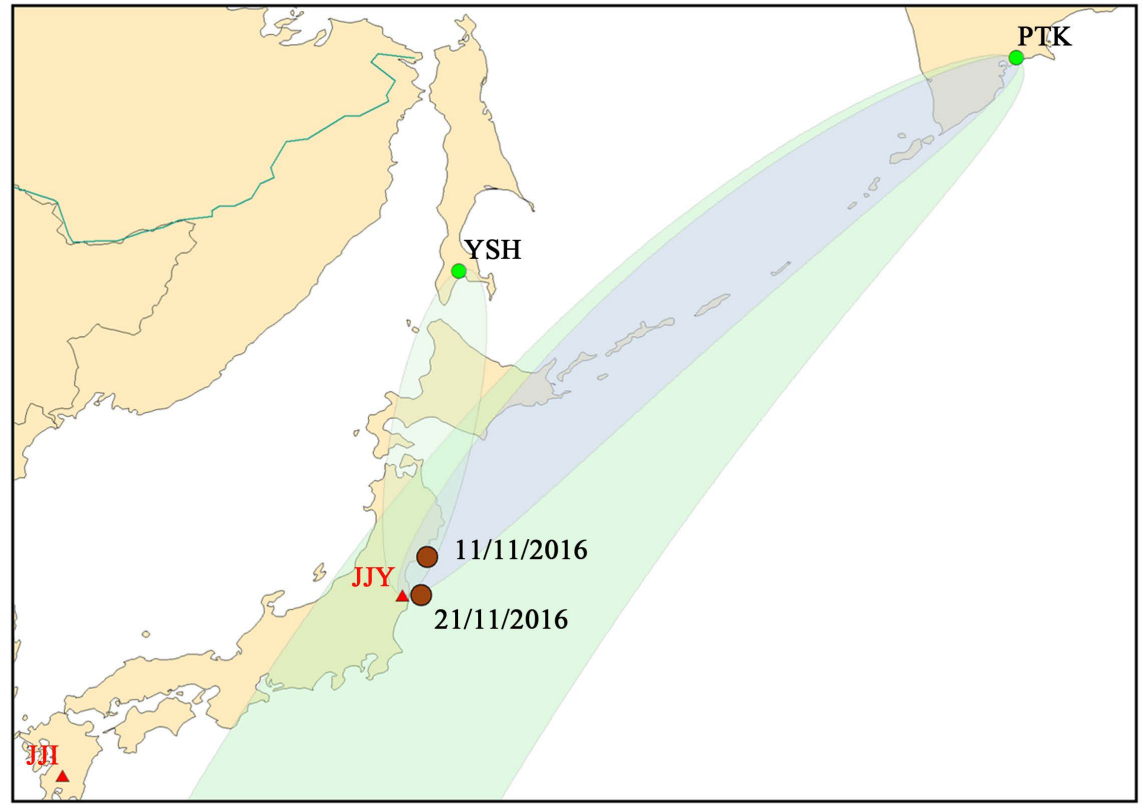

Figure 1. A map showing the position of receivers (PTK and YSH) and transmitter JJY $(40 \mathrm{kHz})$. The NWC transmitter $(19.8 \mathrm{kHz})$ in Australia is beyond the bounds of the figure. The epicenters of EQs are shown by brown circles. Filled ellipses show the sensitivity zones (fifth Fresnel zone) of paths under analysis. 
is Yuzhno-Sakhalinsk $\left(46.95^{\circ} \mathrm{N}, 142.75^{\circ} \mathrm{E}\right.$, abbreviated as YSH in Figure 1) (both in Russia). All these stations are equipped with the identical receivers that register simultaneously the amplitude and phase of MSK (minimum shift keying) and ASK (amplitude shift keying) narrowband modulated signals in the frequency range of $10-50 \mathrm{kHz}$ from several transmitters in the world. The reception is carried out by an electric rod antenna, which measures the vertical electric field components of the subionospheric transmitter signals. We use a sampling frequency of $20 \mathrm{~s}$.

Nearly the same VLF/LF system has been employed at all observing stations in Japan as shown in Figure 2. We can list the observing stations used for our analysis; from north, Suttsu (STU) $\left(42.80^{\circ} \mathrm{N}, 140.23^{\circ} \mathrm{E}\right)$, Nakashibetsu (NSB) $\left(43.54^{\circ} \mathrm{N}, 144.98^{\circ} \mathrm{E}\right)$, Imizu (IMZ) $\left(36.79^{\circ} \mathrm{N}, 137.07^{\circ} \mathrm{E}\right)$, Ito (ITO) $\left(35.00^{\circ} \mathrm{N}\right.$, $\left.139.07^{\circ} \mathrm{E}\right)$, Kamakura $(\mathrm{KMK})\left(35.31^{\circ} \mathrm{N}, 139.55^{\circ} \mathrm{E}\right)$, Togane $(\mathrm{TGN})\left(35.50^{\circ} \mathrm{N}\right.$, $\left.140.38^{\circ} \mathrm{E}\right)$, and Katsuura (KTU) $\left(35.15^{\circ} \mathrm{N}, 140.31^{\circ} \mathrm{E}\right)$. Of course, at each station, we normally detect five VLF/LF transmitter signals; two Japanese (JJY (40 kHz) and JJI $(22.2 \mathrm{kHz})$ in Miyazaki, Kyushu) and three foreign transmitters (NWC (Australia, $19.8 \mathrm{kHz}$ ), NPM (Hawaii, $21.4 \mathrm{kHz}$ ) and NLK (Jim Creek, $24.8 \mathrm{kHz}$ )). Here we present only the VLF data related with the JJY transmitter.

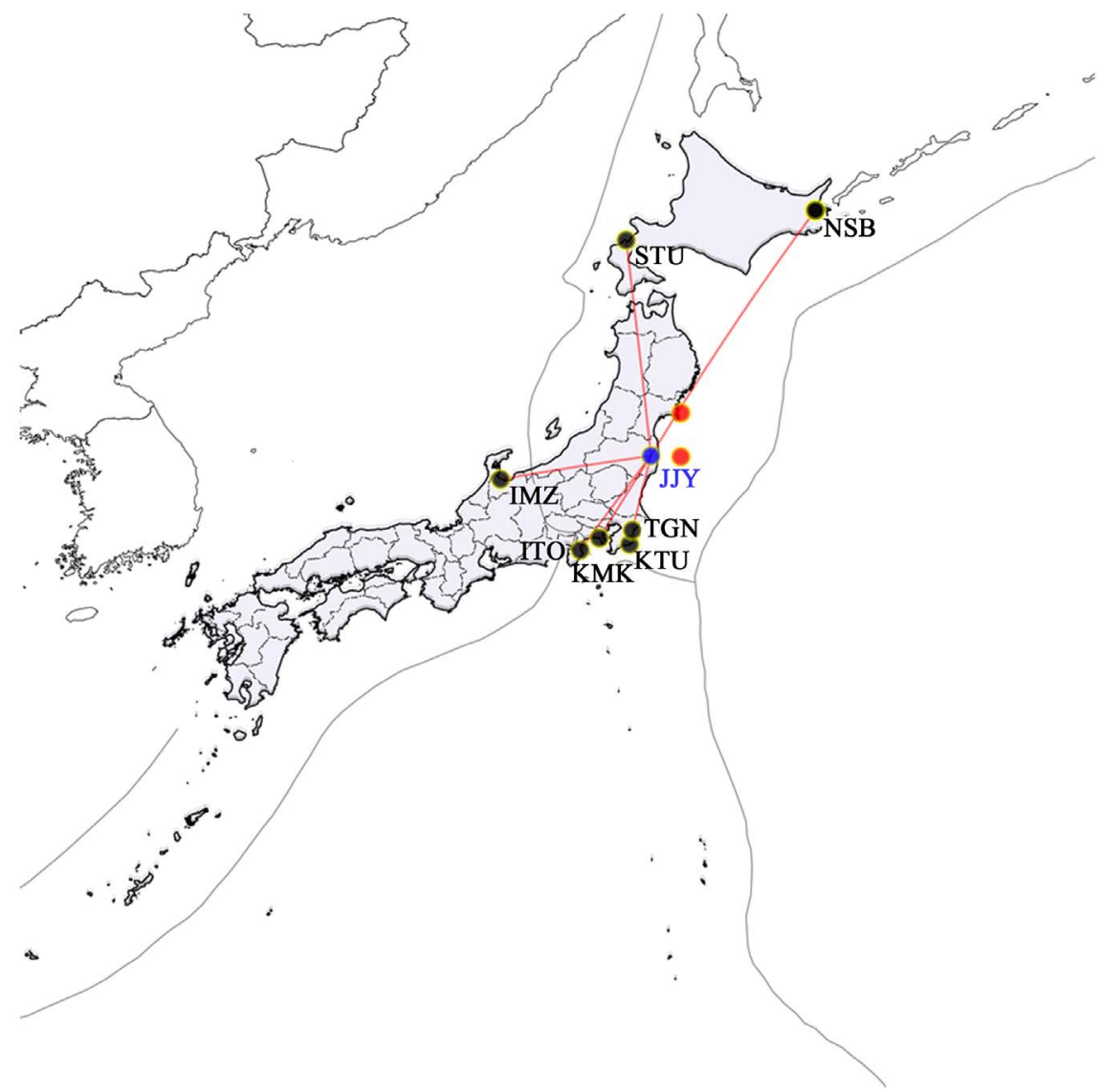

Figure 2. VLF/LF observing stations (NSB, STU, IMZ, ITO, KMK, KTU, TGN) in Japan and the JJY transmitter, and two EQs in the sea. 


\section{VLF Data Analysis}

There are a few conventional analysis methods: 1) terminator time method [8] [20] and 2) nighttime fluctuation method [3] [9] [10] [11]. Both methods have been used simultaneously in some recent papers such as dealing with the recent 2015 Nepal EQ by Maurya et al. (2016) [27].

In this paper we use the latter nighttime fluctuation method: we use a residual signal of amplitude $(\mathrm{dA}(\mathrm{t}))$ calculated as the difference between the current signal $(\mathrm{A}(\mathrm{t}))$ and the monthly average signal $(<\mathrm{A}(\mathrm{t})>)$. The local nighttime is used as LT (local time) $=20 \mathrm{~h}$ to $04 \mathrm{~h}$, and the nighttime average value is used.

\section{Analysis Result}

\subsection{Long-Range Monitoring from Russian VLF Stations}

As shown in Figure 1, Russian VLF stations are located away from the EQ epicenters in the Pacific Ocean side of Japan. However, as seen from Figure 1, the ellipses show the sensitivity zones of the paths under analysis; to be more exact, the fifth Fresnel zones of the great-circle paths. In Figure 1, we can see three propagation paths; JJY-YSH, JJY-PTK and NWC-PTK and NWC-PTK (unfortunately NWC is out of the figure).

Figure 3 illustrates the analysis results for three subionospheric propagation paths (top panel: NWC-PTK, middle panel: JJY-YHS, and bottom panel, JJY-PTK). In each panel, the horizontal dotted lines indicate the conventional threshold of $-2 \sigma$ ( $\sigma$. standard deviation), so that the filled areas highlight the propagation anomalies in VLF signals. The $\mathrm{x}$-axis indicates the days beginning from the 1st of November, 2016 (in UT). The first panel suggests that there were observed significant precursors on 5 and 8 November, several and three days before the first $\mathrm{M}=6.1 \mathrm{EQ}$, and also some after-effects. More enhanced anomalies have been detected for the second panel, which take place on 2 and $3 \mathrm{No}$ vember and 5 - 8 November for the propagation of JJY-YHS. However, no anomaly has been observed for the JJY-PTK propagation path.

As for the larger $\mathrm{M}=6.9 \mathrm{EQ}$, it appears that there are no anomalies (as a decrease in nighttime amplitude) for both propagation paths of NWC-PTK and JJY-YHS. However, we could observe a clear precursory anomaly (as shaded in pink) a few days before the EQ and also an after-effect on 23 November. However, it is not clear whether the anomaly on 23 November is not an after-effect of the main shock, but a precursor to an aftershock on 23 November.

\subsection{Short-Range Monitoring on the Basis of Data from Japanese Stations}

Figure 4 is the summary of the VLF plots in which we can observe clear anomalies from the all VLF stations. We illustrate the temporal evolutions of nighttime VLF amplitude; from the top, 1) JJY-STU (Suttsu), 2) JJY-NSB (Nakashibetsu), 3) JJY-IMZ (Imizu, Toyama prefecture), 4) JJY-ITO (Ito in Izu peninsula), 5) JJY-KMK (Kamakura), 6) JJY-TGN (Togane in Chiba prefecture), 7) JJY-KTU 


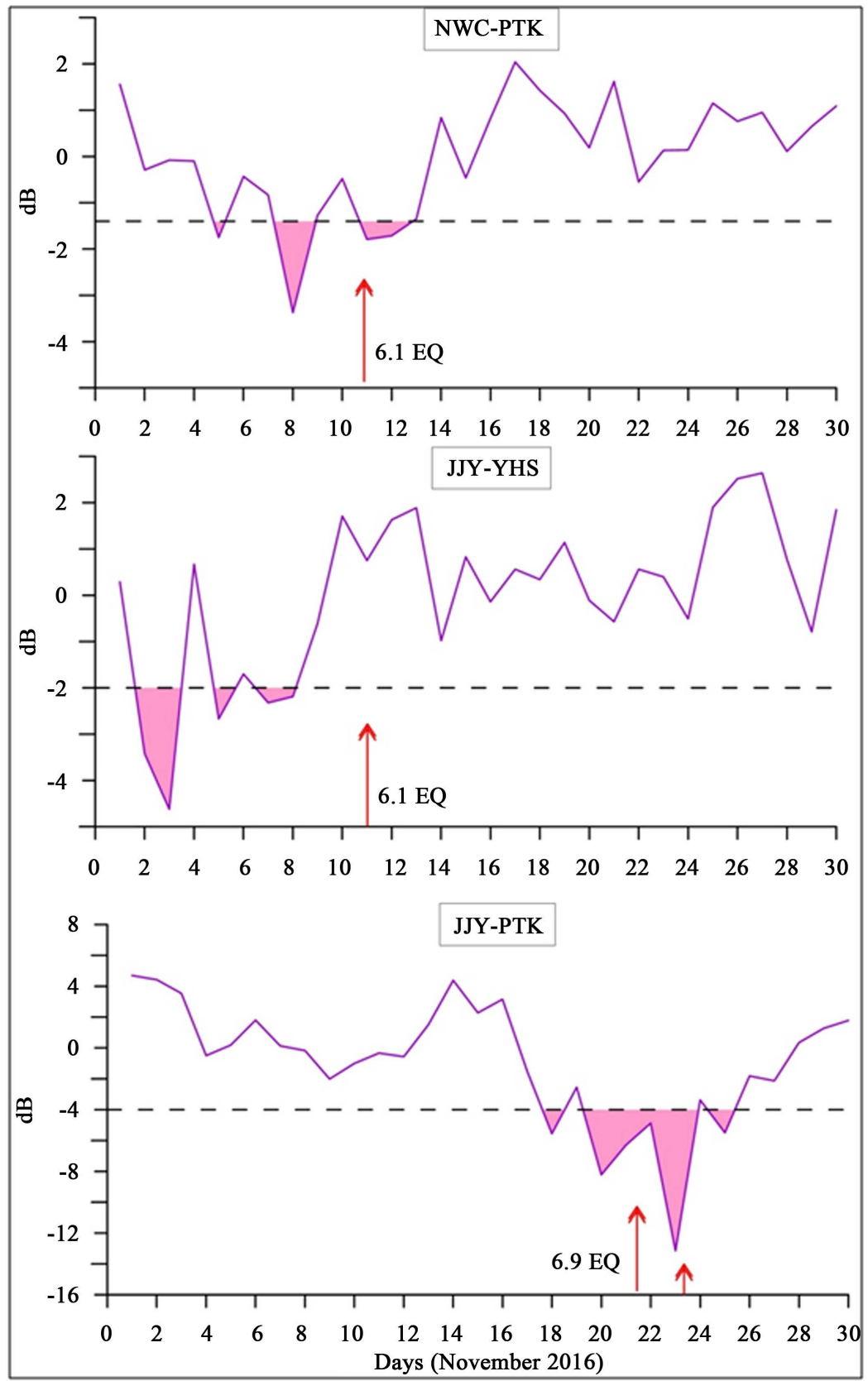

Figure 3. Results of the analysis for the subionospheric paths NWC-PTK, JJY-YSH and JJY-PTK. The ordinate indicates the difference between the current amplitude of signal and monthly mean averaged over night. The dotted horizontal lines show the $-2 \sigma$ level ( $\sigma$ s standard deviation). Axis X shows the days beginning from the 1st of November 2016 (in UT). Filled areas highlight the anomalies in signals, and arrows indicate the occurrence of EQs.

(Katsuura, Chiba prefecture). It is found from Figure 4 that only two propagation paths of JJY-STU and JJY-NSB (northern part of the transmitter JJY) exhibited significant propagation anomalies (as a decrease in the nighttime amplitude) on 2 and 3 November, which are considered to be a precursor to the EQ (6.1) on 11 November. 

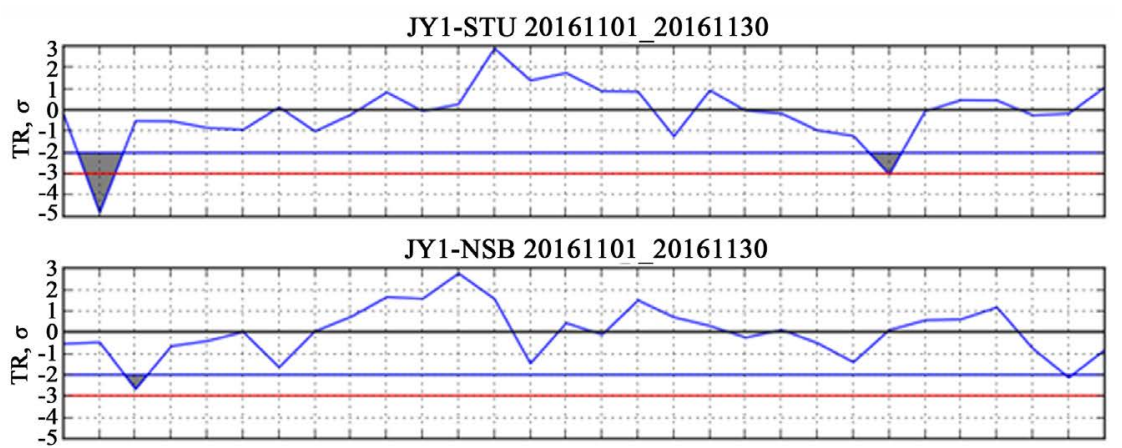

JY1-IMZ 20161101 20161130

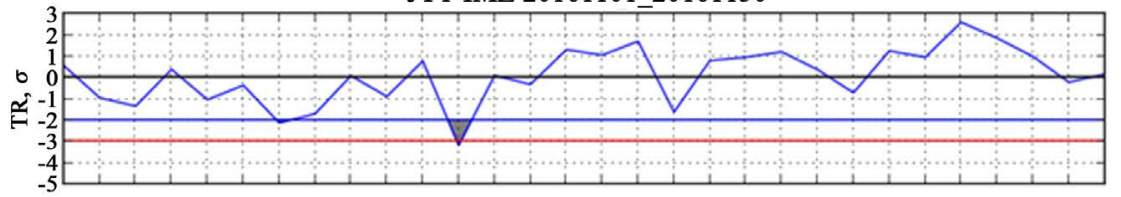

JY1-ITO 20161101 20161130

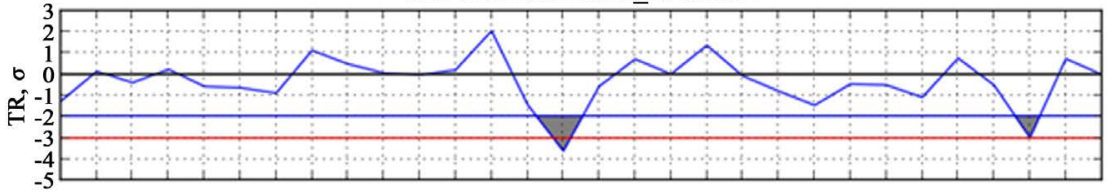

JY1-KMK 20161101_20161130

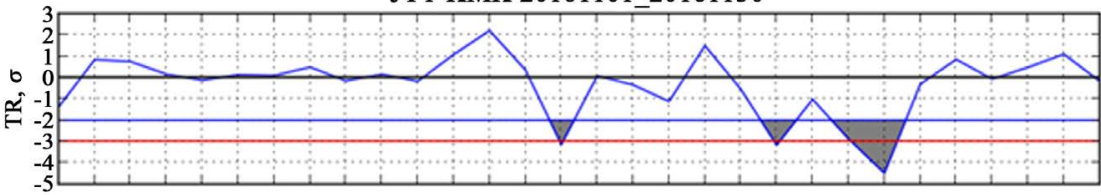

JY1-TGN 20161101_20161130
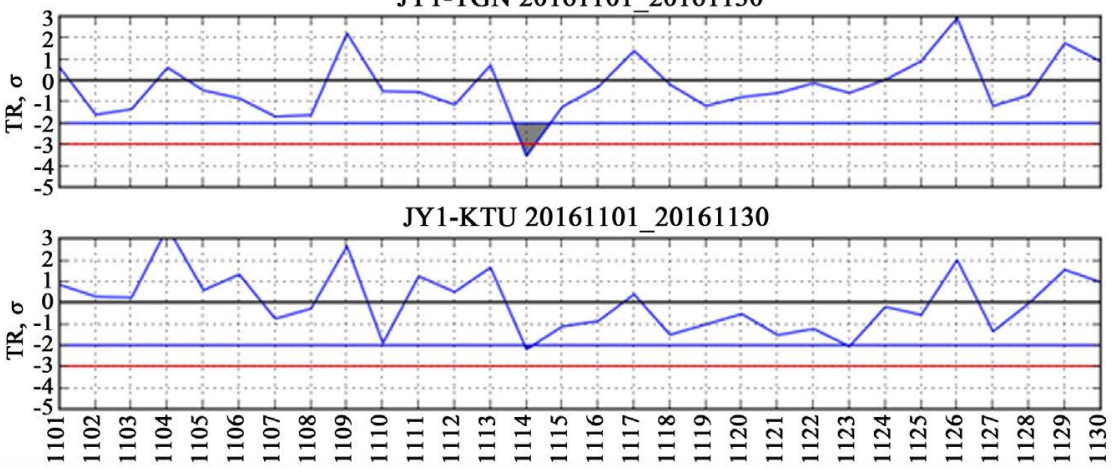

Figure 4. Results of the analysis of subionospheric propagation anomalies associated with the JJY transmitter. From the top, we list the results at the VLF stations (STU, NSB, IMZ, ITO, KMK, TGN and KTU).

On the other hand, we move on to the main EQ event on 21 November. The bottom five panels have indicated the presence of some anomalies. On the JJY-IMZ path, there was observed an anomaly on 12 November, and the following four paths of JJY-ITO, JJY-KMK, JJY-TGN and JJY-KTU all showed propagation anomalies on a few days of 14 to 15 November, about one week before the main shock. The propagation paths of JJY-ITO, JJY-KMK and JJY-TGN had a propagation anomaly with the nighttime average amplitude exceeding $-3 \sigma$ ( $\sigma$. standard deviation). These are all definite to be a precursor to the main shock on 21 November EQ. Additionally, only on a particular path of JJY-KMK, there 
were observed propagation anomalies on 21 November and on 23 and 24 November (probably this is an after-effect).

\section{Comparison with Geomagnetic Activity}

When reporting on the pre-EQ effect in VLF signals, we have to think of the space weather effects. Figure 5 illustrates the temporal evolutions of different space weather effects: From the top, X-ray observed on the GOES satellite, Dst index of geomagnetic activity, high-energy electron and proton fluxes observed on the GOES satellite, and the bottom refers to the atmospheric pressure in the region close to the EQ epicenters. There occurred a small geomagnetic storm on 11 November, but it is a rather small one. Especially, just around the major shock with $M=6.9$ the magnetic activity is found to be very quiet. So that, the VLF propagation anomalies reported in this paper are highly likely to be seismogenic.

\section{Conclusions}

The ionospheric perturbations in possible association with a high seismic activity in November, 2016, have been investigated with the use of our Japan-Pacific (Russian) VLF/LF network. Two EQs (with the last one having magnitude of 6.9) happened: the 1st EQ close to the sea coast, and the 2nd E, in the sea, Pacific Ocean side of Japan. The important point of this paper is the simultaneous use of long-range and short-range VLF monitoring. We have to summarize the VLF findings for two EQs in the Pacific ocean of Japan.

1) As for the November $11 \mathrm{EQ}$, there were observed clear propagation anomalies on the propagation paths of NWC-PTK, JJY-YHS, JJY-STU and JJY-NSB. The VLF data on propagation anomalies on 2 and 3 November are quite similar to all paths (JJY-STU, JJY-NSB, and JJY-YHS).

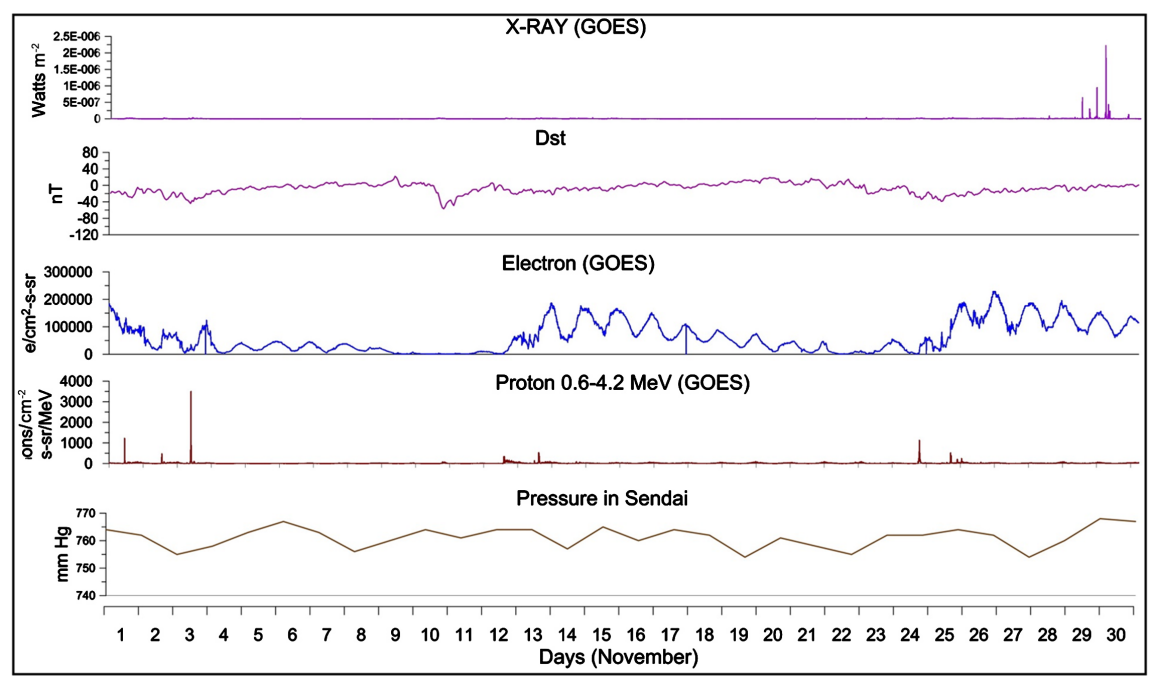

Figure 5. From top to bottom: X-rays, Dst index of magnetic activity, high energy electron fluxes, proton bursts and atmospheric pressure in the region close to the epicenters of EQs. 
2) As for the 2nd large EQ, the VLF stations located south of the transmitter, JJY, could succeed in detecting propagation anomalies on the paths (JJY-IMZ, JJY-ITO, JJY-KMK, and JJY-KTU). The temporal behavior for the JJY-PTK is found to be similar to that of JJY-KMK. However, no responses have been detected on other propagation paths.

3) The lead time for the 1 st event close to the seacoast is about 10 days, while that for the second offshore event is only a few days.

The simultaneous use of long- and short-range monitoring enabled us to think of the important role of the Fresnel zone in finding the lower ionospheric perturbations. Depending on the relative position of great-circle paths (and Fresnel zones) and EQ epicenter, the propagation paths of JJY-YHS, JJY-STU and JJY-NSB showed clear precursors to the 1st EQ because it was located off-shore Miyagi Prefecture. Additionally, we could detect the anomaly on NWC-PTK. Then, the 2nd EQ with bigger magnitude happened offshore in the sea, but relatively close to the transmitter of JJY. In correspondence with this position of the EQ epicenter, all of the VLF stations south of the transmitter (IMZ, ITO, KMK, TGN and KTU) showed clear signatures of precursory ionospheric perturbation, along with the propagation of JJY-PTK.

Asano and Hayakawa (2017) [28] have tried to compare the observational VLF amplitude with the wave-hop theoretical amplitude estimation by changing the reflection heights of 1 hop and 2 hop sky waves for the relevant propagation path, in order to investigate the detailed spatio-temporal evolution of the properties of ionospheric perturbation for the recent 2016 Kumamoto EQ. By using the similar wave-hop computations (details will be published elsewhere), Figure 6 illustrates the area of perturbation (with the VLF reflection height being lowered

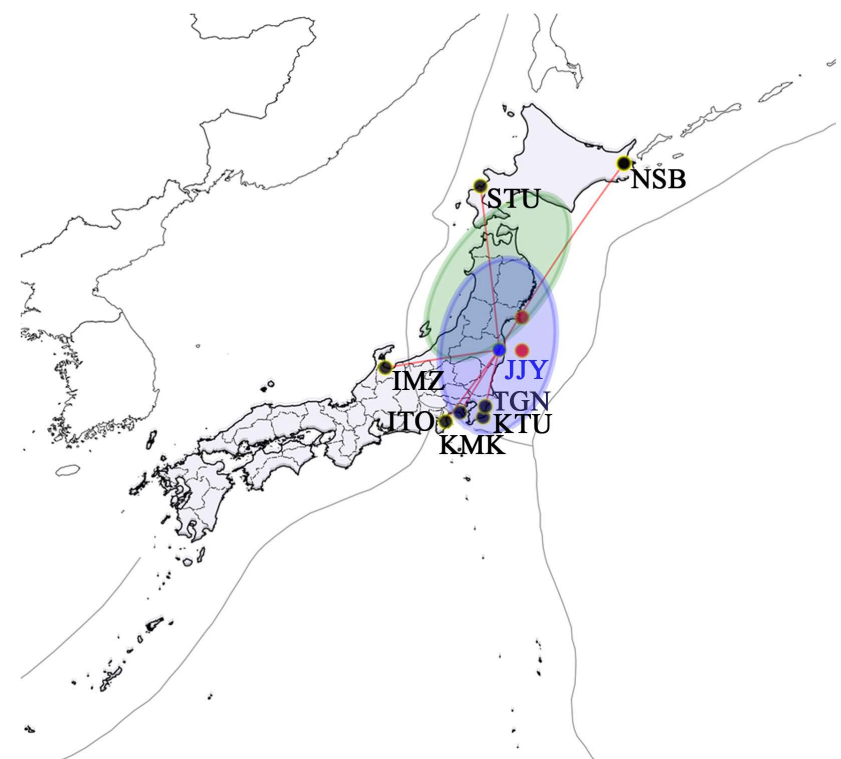

Figure 6. Inference of perturbed regions of the two EQs. Green means the expected area of perturbation for the1st EQ, while the purple one refers to that for the 2nd sea EQ. These areas are considered to be the region with the lower VLF reflection height is lowered by $8 \mathrm{~km}$. 
by $8 \mathrm{~km}$ ) for each of the two EQs. The upper green refers to the 1st EQ, while the lower purple one corresponds to the 2nd sea EQ. For both areas we are not sure about the boundary especially in the ocean side because the VLF data are not available. The distance of the long axis is estimated to be nearly the same, about $170-200 \mathrm{~km}$ for both of the EQs. Any formulas indicating the EQ preparation zone (e.g., [29]) suggest that the size of EQ preparation zone is about twice for the 2nd stronger EQ (bottom EQ in Figure 6) as compared to the 1st EQ (above EQ in Figure 6) because of a difference in their Ms, but the observational fact in Figure 6 is in sharp contrast to this expectation. This may suggest that the preparation zone for an EQ happening in the sea is likely to be much smaller than that for a land EQ when those Ms are the same. We have experienced such an impression for the 2011 Tohoku EQ, because the perturbation area seems to be surprisingly small even though its $M$ is surprisingly large [25]. This may be an important point of the role of sea water when discussing the lithosphere-ionosphere coupling mechanism for EQ in the sea (subduction).

\section{References}

[1] Molchanov, O.A. and Hayakawa, M. (2008) Seismo Electromagnetics and Related Phenomena: History and Latest Results. TERRAPUB, Tokyo, 189 p.

[2] Hayakawa, M. (2015) Earthquake Prediction with Radio Techniques. John Wiley \& Sons, Singapore, 294 p. https://doi.org/10.1002/9781118770368

[3] Hayakawa, M., Kasahara, Y., Nakamura, T., Muto, F., Horie, T., Maekawa, S., Hobara, Y., Rozhnoi, A.A., Solovieva, M. and Molchanov, O.A. (2010) A Statistical Study on the Correlation between Lower Ionospheric Perturbations as Seen by Subionospheric VLF/LF Propagation and Earthquakes. Journal of Geophysical Research: Space Physics, 115, A09305. https://doi.org/10.1029/2009ja015143

[4] Liu, J.Y. (2009) Earthquake Precursors Observed in the Ionospheric F-Region. In: Hayakawa, M., Ed., Electromagnetic Phenomena Associated with Earthquakes, Transworld Research Network, Trivandrum, 187-204.

[5] Pulinets, S.A. and Boyarchuk, K. (2004) Ionospheric Precursors of Earthquakes. Springer, Berlin, $315 \mathrm{p}$.

[6] Freund, F. (2009) Stress-Activated Positive Hole Charge Carriers in Rocks and the Generation of Pre-Earthquakes. In: Hayakawa, M., Ed., Electromagnetic Phenomena Associated with Earthquakes, Transworld Research Network, Trivandrum, 41-96.

[7] Eftaxias, K., Potirakis, S.M. and Contoyiannis, Y. (2017) Four-Stage Model of Earthquake Generation in Terms of Fracture-Induced Electromagnetic Emissions: A Review. In: Chelidze, T., Telesca, L. and Vallianatos, F., Eds., Complexity of Seismic Time Series. Measurement and Applications, Elsevier, Oxford, UK. (In Press)

[8] Hayakawa, M., Molchanov, O.A., Ondoh, T. and Kawai, E. (1996) The Precursory Signature Effect of the Kobe Earthquake on VLF Subionospheric Signals. Journal of the Communications Research Laboratory, Tokyo, 43, 169-180.

[9] Rozhnoi, A., Solovieva, M.S., Molchanov, O.A. and Hayakawa, M. (2004) Middle Latitude LF (40 kHz) Phase Variations Associated with Earthquakes for Quiet and Disturbed Geomagnetic Conditions. Physics and Chemistry of the Earth, 29, 589-598. https://doi.org/10.1016/j.pce.2003.08.061 
[10] Rozhnoi, A., Solovieva, M. and Hayakawa, M. (2013) VLF/LF Signals Method for Searching of Electromagnetic Earthquake Precursors. In: Hayakawa, M., Ed., Earthquake Prediction Studies. Seismo Electromagnetics, TERRAPUB, Tokyo, 31-48.

[11] Rozhnoi, A., Solovieva, M., Parrot, M., Hayakawa, M., Biagi, P.F., Schuwingenschuh, K. and Fedun, V. (2015) VLF/LF Signal Studies of the Ionospheric Reponse to Strong Seismic Activity in the Far Eastern Region Combining the DEMETER and Ground-Based Observations. Physics and Chemistry of the Earth, Parts $A / B / C$, 85-86, 141-149.

[12] Biagi, P.F., Piccolo, R., Castellana, L., Maggipinto, T., Ermini, A., Martellucci, S., Bellecci, C., Perna, G., Capozzi, V., Molchanov, O.A., Hayakawa, M. and Ohta, K. (2004) VLF-LF Radio Signals Collected at Bari (South Italy): A Preliminary Analysis on Signal Anomalies Associated with Earthquakes. Natural Hazards and Earth System Sciences, 4, 685-689. https://doi.org/10.5194/nhess-4-685-2004

[13] Solovieva, M., Rozhnoi, A., Fedun, V., Schwingenschuh, K. and Hayakawa, M. (2015) Ionospheric Perturbations Related to the Earthquake in Vrancea Area on November 22, 2014, as Detected by Electromagnetic VLF/LF Frequency Signals. Annals of Geophysics, 58, A0552.

[14] Chakrabarti, S.K. (2010) Propagation Effects of Very Low Frequency Radio Waves. AIP Conference Proceedings, 362 p.

[15] Hayakawa, M. (2007) VLF/LF Radio Sounding of Ionospheric Perturbations Associated with Earthquakes. Sensors, 7, 1141-1158. https://doi.org/10.3390/s7071141

[16] Hayakawa, M. (2011) Probing the Lower Ionospheric Perturbations Associated with Earthquakes by Means of Subionospheric VLF/LF Propagation. Earthquake Science, 24, 609-637. https://doi.org/10.1007/s11589-011-0823-1

[17] Hayakawa, M., Asano, T., Rozhnoi, A. and Solovieva, M. (2017) VLF/LF Sounding of Ionospheric Perturbations and Possible Association with Earthquakes. In: Ouzounov, D, et al., Eds., Pre-Earthquake Processes. A Multi-Disciplinary Approach to Earthquake Prediction Studies, AGU. (In Press)

[18] Maekawa, S., Horie, T., Yamauchi, T., Sawaya, T., Ishikawa, M., Hayakawa, M. and Sasaki, H. (2006) A Statistical Study on the Effect of Earthquakes on the Ionosphere, Based on the Subionospheric LF Propagation Data in Japan. Annales Geophysicae, 24, 2219-2225. https://doi.org/10.5194/angeo-24-2219-2006

[19] Kasahara, Y., Muto, F., Horie, T., Yoshida, M., Hayakawa, M., Ohta, K., Rozhnoi, A., Solovieva, M. and Molchanov, O.A. (2008) On the Statistical Correlation between the Ionospheric Perturbations as Detected by Subionospheric VLF/LF Propagation Anomalies and Earthquakes. Natural Hazards and Earth System Sciences, 8 , 653-656. https://doi.org/10.5194/nhess-8-653-2008

[20] Chakrabarti, S.K., Sasmal, S. and Ray, S. (2013) ICSP Detections of Anomalous VLF Radio Wave Signals Prior to Major Earthquakes. In: Hayakawa, M., Ed., Earthquake Prediction Studies: Seismo Electromagnetics, TERRAPUB, Tokyo, 49-55.

[21] Ohta, K., Watanabe, N. and Hayakawa, M. (2005) The Observation of ULF Emissions at Nakatsugawa in Possible Association with the 2004 Mid Niigata Prefecture Earthquake. Earth, Planets and Space, 57, 1103-1108.

https://doi.org/10.1186/BF03351889

[22] Hayakawa, M., Ohta, K., Maekawa, S., Yamauchi, T., Ida, Y., Gotoh, T., Yonaiguchi, N., Sasaki, H. and Nakamura, T. (2006) Electromagnetic Precursors to the $2004 \mathrm{Mid}$ Niigata Prefecture Earthquake. Physics and Chemistry of the Earth, 31, 356-364. 
[23] Horie, T., Maekawa, S., Yamauchi, T. and Hayakawa, M. (2007) A Possible Effect of Ionospheric Perturbations Associated with the Sumatra Earthquake, as Revealed from Subionospheric Very-Low-Frequency (VLF) Propagation (NWC-Japan). International Journal of Remote Sensing, 28, 3133-3139.

https://doi.org/10.1080/01431160601094476

[24] Ohta, K., Watanabe, N. and Hayakawa, M. (2007) The Observation of Ultra-Low Frequency Emissions at Nakatsugawa, Japan, in Possible Association with the Sumatra, Indonesia, Earthquake. International Journal of Remote Sensing, 28, 3121-3131. https://doi.org/10.1080/01431160601091779

[25] Hayakawa, M., Rozhnoi, A., Solovieva, M., Hobara, Y., Ohta, K., Schekotov, A. and Fedorov, E. (2013) The Lower Ionospheric Perturbation as a Precursor to the 11 March 2011 Japan Earthquake. Geomatics, Natural Hazards and Risk, 4, 275-287. https://doi.org/10.1080/19475705.2012.751938

[26] Hayakawa, M., Schekotov, A., Potirakis, S. and Eftaxias, K. (2015) Criticality Features in ULF Magnetic Fields Prior to the 2011 Tohoku Earthquake. Proceedings of the Japan Academy, Ser. B, 91, 25-30.

[27] Maurya, A.K., Venkatesham, K., Tiwari, P., Vijaykumar, K., Singh, R., Singh, A.K. and Ramesh, D.S. (2016) The 25 April 2015 Nepal Earthquake: Investigation of Precursor in VLF Subionospheric Signal. Journal of Geophysical Research: Space Physics, 121, 10,403-10,416. https://doi.org/10.1002/2016JA022721

[28] Asano, T. and Hayakawa, M. (2017) On the Lower Ionospheric Perturbation for the 2016 Kumamoto Earthquakes on the Basis of VLF Propagation Data Observed at Multiple Sations and Wave-Hop Theoretical Computations. Proceedings of International Workshop on Earhtquake Preparation Process Observation, Validation, Modeling, Forecasting, Chiba, 26-27 May 2017, 34.

[29] Ruzhin, Y.Y. and Depueva, A.K. (1996) Seismo Precursors in Space as Plasma and Wave Anomalies. Journal of Atmospheric Electricity, 16, 271-288. 